\title{
Quando as (hetero)normas estremecem o cotidiano da Educação Infantil: conversas com professoras sobre as marcas de gênero expressas nas interações entre crianças ${ }^{4}$
}

\begin{abstract}
Resumo: Fruto de pesquisa recentemente concluída, o estudo apresentado neste texto teve como objetivo investigar, sob a ótica de professoras da Educação Infantil, como as marcas de gênero se fazem presentes nos momentos de interação entre crianças de uma escola da rede pública de Itaperuna/Rio de Janeiro. Haja vista a necessidade de se desestabilizar o regime heterocentrado que busca, incansavelmente, normatizar corpos, gêneros e sexualidades, esta pesquisa é ancorada numa proposta que busca fomentar outras formas de olhar/(re)pensar o mundo em prol da necessidade de se criar estratégias de enfrentamento à heteronormatividade. Para isso, foram realizadas conversas com professoras da Educação Infantil dessa escola pública, que evidenciaram a forte presença das marcas de gênero no cotidiano educacional. Os achados da pesquisa apontaram para a necessidade de se buscar estratégias/brechas capazes de promover diálogos mais abertos entre a escola, as crianças e as famílias, com o objetivo de negociar sentidos que possam ser potentes para diminuir a incidência de preconceitos e discriminações em torno das questões de gênero que estremecem o cotidiano da Educação Infantil.
\end{abstract}

Palavras-chave: Educação Infantil. Gênero. Heteronormatividade.

\section{When the (hetero)norms shudder the daily life of Children's Education: conversations with teachers about the gender marks expressed in interactions among children}

Abstract: As a result of a recently completed research, the study investigated, from the point of view of teachers of Children's Education, how gender marks are present in the interaction among children of a public school in Itaperuna/Rio de Janeiro. Given the need to destabilize the heterocentric regime that seeks, unceasingly, to normalize bodies, genders and sexualities, this research is anchored in a proposal that encourages other ways of looking/(re)thinking the world in favor of the need to create strategies to contest heteronormativity. In order to do this, debates held with teachers from this public school, which evidenced the strong presence of gender marks in the school's daily quotidian. The research findings pointed to the need to find strategies/gaps capable of promoting more open dialogues between school, children and families, in order to negotiate meanings that may be potent in reducing the

\footnotetext{
Graduanda do curso de Pedagogia da Universidade Federal do Estado do Rio de Janeiro (UNIRIO). E-mail: paula832riosf@gmail.com

2 Pós-doutorando no Programa de Pós-Graduação em Educação da Universidade do Estado do Rio de Janeiro (ProPEd/UERJ). Membro do Grupo de Estudos em Gênero e Sexualidade e(m) Interseccionalidades (Geni). Bolsista CNPq/PDJ. E-mail: junnior_2003@yahoo.com.br

${ }^{3}$ Doutorando no Programa de Pós-Graduação em Educação da Universidade do Estado do Rio de Janeiro (ProPEd/UERJ). Membro do Grupo de Estudos em Gênero e Sexualidade e(m) Interseccionalidades (Geni). Bolsista FAPERJ. Email:felipesilvaponte@gmail.com

4 Gostaríamos de agradecer as/os pareceristas da Revista Zero-a-Seis, cujo olhar sensível, atento e crítico proporcionou o enriquecimento deste trabalho.
} 
incidence of prejudices and discrimination regarding gender marks that shake the daily life of the Children's Education.

Keywords: Children's Education. Gender. Heteronormativity.

\author{
Introdução
}

Problematizações iniciais sobre gênero e sexualidade na educação

[...] aqueles que insistem que o gênero tem sempre de aparecer de uma maneira, que buscam por criminalizar ou patologizar aqueles que vivem seus gêneros ou suas sexualidades de maneiras não normativas, estão eles mesmos agindo como polícia ainda que não pertençam a nenhuma força policial ou manejem uma arma ${ }^{5}$.

Judith Butler

vigilância em torno da fabricação dos corpos, gêneros e sexualidades é uma prática cotidiana
colocada em funcionamento para a manutenção da ordem heteronormativa vigente. Aqueles
que se tornam polícias de gênero agem para manter intacta a supremacia das (hetero)normas, contribuindo para fortalecer a figura hegemônica do "homem" e da "mulher" (BUTLER, 2017). As (hetero)normas tentam enquadrar e classificar corpos por meio de "redes educativas" complexas (ALVES, 2012), tais como: família, escola, trabalho, sindicatos, movimentos sociais, partidos políticos etc. Contudo, há corpos que desviam dos enquadramentos das (hetero)normas impostas por essas redes. Podemos dizer que os corpos relegados à condição de "desviantes" e "estranhos" (LOURO, 2013) são corpos cujas "vidas precárias" (BUTLER, 2015) não merecem ser vividas, não merecem ter acesso à cidadania, nem circular pelos espaços públicos e fazer uso dos bens materiais da própria cidade. $\mathrm{Na}$ presente pesquisa, caminhamos na contramão do regime heterocentrado (PRECIADO, 2014) com o propósito de tencionar práticas e convenções sociais que fazem reinar a normatização da vida.

É importante reiterar que as expectativas sociais diante do corpo do sujeito são acompanhadas muito antes de seu nascimento, quando ainda é um feto. Através da ecografia, exame que possibilita acompanhar o crescimento do bebê, a nomeação do corpo, por meio da identificação de seu órgão genital, age com o objetivo de enquadrá-lo dentro de um gênero específico, aguçando, desde então, o imaginário da família e da sociedade em torno da criação de um bebê-menino ou bebê-menina (BENTO, 2011; LOURO, 2013). O exame ecográfico é considerado "uma tecnologia célebre por ser descritiva, mas que não é senão prescritiva” (PRECIADO, 2014, p. 130).

${ }^{5}$ BUTLER, 2017, P. 35. 
O presente artigo, fruto de pesquisa recentemente concluída, está diretamente interligado com as diversas experiências docentes no campo da Educação Infantil, mais especificamente aquelas experiências atravessadas pelas marcas de gênero na interação de crianças pequenas. Enquanto educadorespesquisadores, tivemos a oportunidade de investigar a forma como as atividades realizadas na Educação Infantil ecoam no âmbito familiar ("por que você entregou uma folha rosa para meu filho? Rosa é cor de menina?" / "meu filho é homem, professora, não é mulherzinha"), o que nos motiva a provocar questionamentos frente às construções socioculturais da categoria gênero. Entretanto, essas questões nem sempre restringem-se ao âmbito familiar, na medida em que, muitas das vezes, a própria instituição educacional reforça a supremacia das normas regulatórias de gênero, delimitando quais as atividades pedagógicas, posturas e comportamentos que, na concepção das professoras, seriam condizentes para cada um dos gêneros das crianças (SEFFNER, 2013; MISKOLCI, 2013; COUTO JUNIOR, 2017).

Não raramente temos tido a oportunidade de presenciar, no cotidiano escolar, expressões que demonstram a presença de (hetero)normas regulatórias que delimitam os comportamentos sociais aceitáveis para meninos e meninas, enquadrando essas crianças, mesmo aquelas de pouca idade, dentro de moldes normativos prescritivos: "vamos descer para lanchar, turma! Façam duas filas, meninas de um lado e meninos de outro", "fulana, já disse para comportar-se como uma menina" e "vamos lá, meninos no futebol e meninas na queimada!'. Caminhando nessa direção, Kramer (2007) também registrou inúmeras falas de professoras de uma tradicional instituição privada no Rio de Janeiro: “'Homem não chora.' 'A mesa das meninas tá tão linda, tá tão quietinha hoje? 'Senta assim direitinho, que nem menininha educada.'[...] 'Você não pode jogar futebol, não, porque vai se sujar toda.'[...] 'Olha só o caderno dele, tá tão caprichado... nem parece coisa de menino!"' (p. 179, grifos nossos). Essas frases, enunciadas no cotidiano da Educação Infantil, nos remetem para o argumento de que não há como universalizar/essencializar o que seria masculino ou feminino, pois os aspectos socioculturais sobre o que é ser homem ou mulher se alteram tempo e espacialmente (BELLO; FELIPE, 2010). A vida social, através de suas práticas e valores, determina os comportamentos e atitudes que, num determinado tempo e espaço, são mais socialmente aceitos para cada gênero.

Os enunciados explicitados no parágrafo anterior nos fazem perceber que é imprescindível colocar em pauta assuntos muitas vezes considerados tabus em sala de aula, com a intenção de provocar reflexões que sejam potentes para subverter normas e convenções culturais, que num primeiro momento, parecem incontestáveis. Esses discursos nos direcionam para as indagações de Preciado (2014): "Se sou homem ou mulher? Esta pergunta reflete uma obsessão ansiosa [...] Qual? A de querer reduzir a verdade do sexo a um binômio” (p. 223). Essas indagações são discutidas ao longo desse texto, preocupado em problematizar as obsessões sociais que reforçam a necessidade de que todos os sujeitos sejam inseridos em um determinado gênero e, consequentemente, ajam de acordo com as (hetero)normas.

No trabalho com os cotidianos educacionais envolvendo crianças pequenas,

É fundamental que se perceba a criança como um sujeito que pensa, age, pertence a uma classe social, está inserido em um contexto, que constrói e se constrói na cultura, que produz e é produtor de linguagem, ou seja, a criança é um ser social, histórico, político e cultural. E isso é fato. E é por essa criança que se deve lutar. Não para que ela 
seja o adulto de amanhã, e sim, porque ela é um sujeito hoje (CARVALHO, 1997, p. 122-123).

Conceber a criança enquanto um ser sócio-histórico nos convida a reconhecer seu protagonismo nas práticas sociais e sua legitimação na participação da vida cultural e política. Todavia, não somos ingênuos e reconhecemos o desafio dessa participação considerando que as normas regulatórias de gênero agem mais fortemente sobre elas, principalmente quando frequentam espaços em que as práticas sociais heteronormativas encontram-se presentes (WARNER, 2004). Não raramente, a relação assimétrica estabelecida na interação adulto-criança enquadra a criança em moldes (hetero)normativos que se caracterizam enquanto verdadeiras mordaças na constituição de suas subjetividades. A relação patriarcal e "adultocêntrica" favorece a "desqualificação da voz das crianças na configuração dos seus mundos de vida" (SARMENTO, 2005, p. 370).

O objetivo do presente estudo é investigar, sob a ótica de professoras da Educação Infantil, como as marcas de gênero se fazem presentes nos momentos de interação entre crianças de uma escola da rede pública de Itaperuna. Para isso, no primeiro semestre de 2017, foram realizadas conversas com quatro professoras que trabalham em turmas da Educação Infantil de uma instituição municipal localizada no Estado do Rio de Janeiro/RJ6. As quatro professoras participantes do trabalho de campo apresentam idades variando entre 30 e 40 anos, todas formadas em Pedagogia, com tempo médio de 10 anos de trabalho no cotidiano da Educação Infantil. Vale ressaltar ainda que duas professoras trabalham em turmas cuja faixa etária das crianças é de 4 a 5 anos, uma atua no trabalho com crianças de 3 a 4 anos e uma atua em turmas com crianças que apresentam idades variando entre 2 e 3 anos. O roteiro da conversa foi previamente estruturado com questões importantes para nortear o diálogo com as professoras, no entanto, vale ressaltar que outras questões emergiram na medida em que o diálogo foi sendo construído com os sujeitos durante a imersão em campo. Diante do teor das conversas, optamos pelo uso de nomes fictícios para garantir o anonimato das professoras.

No que se refere aos aspectos teórico-metodológicos, a pesquisa é amparada nos pressupostos da abordagem histórico-cultural. Essa abordagem apresenta inúmeras possibilidades de articulação teórica através do diálogo com Walter Benjamin, Lev S. Vigotsky e Mikhail Bakhtin. Dentro deste contexto, nos inspiramos principalmente nos trabalhos de Freitas (2002, 2009), que articula Vigotsky com Bakhtin e propõe a pesquisa dialógica. No campo de estudos da infância, vale destacar ainda que os trabalhos de Kramer (2004), Pereira (2012, 2015), Jobim e Souza e Salgado (2008), Pereira, Salgado e Jobim e Souza (2009), para citar alguns, são fundamentados teórico e metodologicamente na abordagem históricocultural.

Com base nos princípios do dialogismo e alteridade, entendemos que a relação com o outro, no convívio social, é imprescindível na produção de conhecimento. Essa relação é baseada na premissa de que quando interagimos com o outro entramos no campo das revelações e das descobertas (BAKHTIN,

${ }^{6}$ A primeira autora do texto conduziu o trabalho de campo, enquanto que o segundo autor orientou o trabalho de pesquisa em questão. 
2011). O encontro com o outro constitui-se como um momento único, irrepetível, com cada ponto de vista ampliando nosso olhar sobre a vida e ressignificando a forma como afetamos e nos deixamos afetar pelo outro (COUTO JUNIOR; OSWALD, 2016). Isso não significa que as provocações reflexivas desencadeadas com os sujeitos no trabalho de campo devam ser sempre convergentes, uma vez que cada ponto de vista parte de um lugar sociocultural distinto (AMORIM, 2008). Assim sendo, essa abordagem de pesquisa reconhece que a "construção da consciência de si é fruto do modo como compartilhamos nosso olhar com o olhar do outro, criando, desta forma, uma linguagem que permite decifrar mutuamente a consciência de si e do outro no contexto das relações sociais, históricas e culturais" (JOBIM E SOUZA; ALBUQUERQUE, 2012, p. 113). Em conformidade com o pensamento desses autores, Pereira (2012) mostra que é na diferença que se estabelece a perspectiva dialógica na pesquisa, conferindo às ciências humanas uma dimensão alteritária.

Uma pesquisa baseada na abordagem histórico-cultural caminha numa direção oposta àquela que dá a "voz aos sujeitos" e que busca "validar verdades" (COUTO JUNIOR; FERREIRA; OSWALD, 2017). Reconhecendo que pesquisador e sujeitos são seres expressivos e falantes (BAKHTIN, 2011; FREITAS, 2002), é incoerente "dar a voz" a pessoas que, a priori, já estão autorizadas a falar e que buscam, através do diálogo, ressignificar pontos de vista prévios em prol da produção de novas interpretações sobre o mundo. Somando-se a isso, longe de ir a campo para "coletar dados" que sejam analisados à luz de um quadro teórico rígido e inflexível, reconhecemos o quanto o dialogismo e a alteridade possibilitam compreender que a interação entre pesquisador e sujeitos evidencia o aspecto de inacabamento do outro. Isso porque pesquisador e sujeitos modificam-se permanentemente na relação que estabelecem em conjunto, com o diálogo constituindo-se através de perguntas e respostas sempre provisórias e negociáveis (COUTO JUNIOR; FERREIRA; OSWALD, 2017). Nesse contexto, entendemos que a criação de vínculos sociais e afetivos entre pesquisados e sujeitos são capazes de colocar em prática um diálogo horizontalizado que refuta "a" verdade e a busca incessante pelos "pontos finais". Portanto, o processo dialógico amparado pela abordagem sócio-histórica é construído entre duas ou mais consciências, com reflexões sempre provisórias que almejam a troca de experiências.

Esta pesquisa visa contribuir com o campo de estudos de gênero e sexualidade em contextos escolares, com ênfase nas relações de gênero presentes na Educação Infantil. Para isso, buscamos tecer reflexões em torno da desconstrução das masculinidades e feminilidades hegemônicas impostas pela sociedade, estimulando as professoras participantes do estudo a (re)pensarem as questões engendradas pelas marcas de gênero no cotidiano da Educação Infantil. Almejamos que as reflexões tecidas ao longo deste trabalho de pesquisa possam ser convidativas a outras formas de olhar/(re)pensar o mundo, desestabilizando o olhar (hetero)normativo que busca, incansavelmente, enquadrar corpos, gêneros e sexualidades dentro dos moldes da heterossexualidade hegemônica.

Nesse sentido, a tessitura das reflexões realizadas neste trabalho incide diretamente na necessidade de se articular problematizações em torno das questões de gênero ancoradas ao contexto das infâncias, chamando atenção para um campo que ainda é bastante incipiente nos estudos de gênero e sexualidade 
em educação no Brasil. Nesse campo, vale destacar os trabalhos que discutem a constituição da sexualidade das crianças através das pedagogias escolares utilizadas por professoras (RIBEIRO; SOUZA; SOUZA, 2004); as representações hegemônicas de corpo, gênero e geração construídas e reiteradas cotidianamente no contexto da Educação Infantil (GUIZZO; BECK, 2014); a desconstrução das masculinidades e feminilidades hegemônicas no campo das infâncias (SILVA; PARAÍSO, 2017; BELLO; FELIPE, 2010); a discussão sobre o tema gênero e sexualidade, com crianças, em atividades lúdicas realizadas na forma de oficinas (PEIXOTO, 2013); a análise cultural de um livro paradidático infantil com a intenção de desconstruir a normatização do sexo e da sexualidade (FURLANI, 2007); além da importância do tema criança e infância no audiovisual na promoção de práticas subversivas que possam questionar as normas heterossexuais no cotidiano educacional (SIERRA; CÉSAR, 2016). Esses estudos apresentam elementos reflexivos que favorecem (re)pensarmos, com urgência, o cuidado com o planejamento das atividades pedagógicas numa época em que o fundamentalismo religioso, através da chamada "ideologia de gênero", busca impedir que o tema corpo-gênero-sexualidade seja discutido/mencionado nos cotidianos educacionais.

A análise interpretativa do material empírico produzido com as professoras está apresentada em três partes na seção a seguir. Na primeira, discutimos as marcas de gênero que se encontram presentes no cotidiano da Educação Infantil, com ênfase na interação estabelecida entre as crianças. Em seguida, discutimos com as professoras as diferentes possibilidades e os desafios de se trabalhar gênero no cotidiano escolar. Na terceira parte, ressaltamos a importância da construção de um espaço acolhedor na Educação Infantil que favoreça amplas possibilidades de experimentação por parte das crianças, potencializando suas múltiplas e variadas formas de ver-sentir o mundo.

\section{Análise interpretativa do material empírico produzido com as professoras}

\section{"Tive um aluno aqui que a mãe estava achando que ele estava ficando 'afeminado"”}

As professoras participantes do estudo, ao serem interpeladas sobre as marcas de gênero presentes nos momentos de interação das crianças durante as atividades na escola, relatam:

$$
1
$$

Júlia: Todos os meninos e meninas brincam e andam juntos. Eles ainda não têm maldade nessa separação. [...] Se um menino leva um carrinho, todos brincam. As meninas não veem problema. Elas não têm aquela coisa "menina não pode brincar de carrinho". Mas isso não acontece quando uma menina leva uma boneca, por exemplo. Quando isso acontece, no máximo uns dois meninos se aproximam para brincar e não veem problema nenbum. Mas tem uns que não sentam para brincar com a boneca.

[...] Eu acho que o brincar da criança é de acordo com o olhar do adulto. À medida que o adulto vai orientando "você não pode isso ou aquilo" é o que ele vai passar para a criança. Então, aquele adulto que não passa isso para a criança, ela vai vivenciar um pouquinho de tudo e depois vai selecionar o que mais gosta de brincar ou não.

\footnotetext{
7 Foge do foco deste trabalho discutir com mais amplitude aquilo que determinados grupos religiosos ultraconservadores vêm denominando de "ideologia de gênero". Para maiores reflexões sobre isso, vale citar os trabalhos de Paraíso (2016), Rosado-Nunes (2015), Junqueira (2017), Amaro (2017) e Cornejo-Valle e Pichardo (2017).
} 
Fernanda: Meninos e meninas brincam todos juntos. E aqui, como o espaço é muito grande, a área do parquinho é muito extensa, o que se vê é que eles se separam de acordo com o que querem brincar, independente de serem meninos ou meninas.

Pesquisadora: E como você acha que as crianças se percebem "meninos" e "meninas"?

Fernanda: Ah, isso com certeza já vem de casa preestabelecido. Eles já chegam dentro de sala de aula com essa noção. E às vezes acontece de falar que tal coisa é só para as meninas e tal coisa só para os meninos. Na minha turma, por exemplo, tem um menino com cabelo grande. Na altura do ombro. E ele vem a escola com arco no cabelo, com faixa. Teve um dia que ele veio com aquele "coque samurai". E estava preso com buchinha. Os meninos começaram a questionar que ele não deveria usar aquilo, pois era de menina. Tão pequenos e já vêm com essa separação. Tive que explicar que servia tanto para um quanto para outro. E boje, ele já pode ir com coisas no cabelo e as crianças já não falam mais nada.

3

Pesquisadora: Qual a regra do brincar as crianças usam para definir quem pode ou não participar? Andréia: Depende da brincadeira. Por exemplo, tem vez que os meninos querem brincar de dinossauro. E uma menina quer brincar junto. Eles não deixam. [...] $O$ ano passado eu tive um aluno aqui que a mãe estava achando que ele estava ficando "afeminado". A preocupação dela era porque a avó que cuidava mais dele e ela não estava deixando ele se desenvolver. A avó o protegia muito. E vejo que essa preocupação é sempre com menino. Dele virar gay, dele ser afeminado. E com menina não se tem muito essa preocupação. Elas podem brincar mais livremente. Não sei o motivo. Mas isso vem de casa.

4

Michele: Na hora da merenda tem separação por gênero. Eu só não sei o motivo de no refeitório eles separarem mesa só com meninos e mesa só com meninas. Comecei a trabalhar aqui esse ano. E faço, pois vejo que todas fazem dessa forma. E, percebo que quando uma menina senta na mesa que é para os meninos, elas tiram e colocam na mesa das meninas.[...] Eu trabalho com o Maternal. São muito novos e já vêm de casa falando o que é de menino e de menina. O que podem ou não brincar e fazer. Por exemplo, tenho um aluno que só gosta de brincar de boneca. Ele chegou aqui no início do ano e na hora da caixa de brinquedos, foi a boneca que chamou a atenção dele e ele pegou para brincar. Foi natural para ele. Os outros me chamaram para ver, esperavam que eu fosse brigar com ele por acharem que menino não pode brincar de boneca. Então eu tive que falar que não tem problema. Para as crianças perceberem que não tem essa de coisa especifica para cada gênero. De onde vem essa percepção? De casa, pois eu não falo isso dentro de sala.

O conceito de gênero, ao considerar os fatores socioculturais, revela que a construção das masculinidades e feminilidades são determinadas pelas práticas sociais de um determinado tempo e espaço, ou seja, não são universais (MEYER, 2010). Ao analisar as marcas de gênero no contexto de nossa cultura, Louro (2000) evidencia que a "manifestação de afetividade entre meninos e homens é alvo de uma vigilância muito mais intensa do que entre as meninas e mulheres" (p. 18). Isso pode ser visto mais claramente quando a professora Andréia comenta que "essa preocupação [com as questões de gênero] é sempre com menino. De ele virar gay. De ele ser afeminado. E com menina não se tem muito essa preocupação. Elas podem brincar mais livremente". Baseada nas premissas ideológicas do regime patriarcal, nossa cultura reforça a supremacia masculina, colocando o homem num patamar social superior ao da mulher (PRECIADO, 2014). Quando meninos e homens têm posturas semelhantes àquelas que são comumente caracterizadas como sendo posturas de uma menina ou mulher, muitas vezes isso traz graves consequências sociais como a homofobia (BORRILLO, 2010). Na escola, quando a "produção das identidades de gênero [é] marcada 
por uma profunda violência, passamos a entender a homofobia enquanto uma prática e um valor que atravessa e organiza as relações sociais, distribui poder e regula comportamentos" (BENTO, 2011, p. 556).

A força com a qual a masculinidade hegemônica ecoa nas práticas socioculturais cotidianas faz estremecer o trabalho com as crianças na Educação Infantil. As professoras evidenciaram que os meninos geralmente não utilizam o lápis de cor rosa, argumentando que é uma cor imprópria para seu gênero. Somando-se a isso, todas as professoras compreendem que essa atitude vem de casa, na "estereotipização" de gênero. Conferindo a essa "maneira naturalizada" de pensar, ainda existem muitos aspectos sociais que são atribuídos a meninos e meninas, reforçando, assim, o binarismo de gênero (BELLO; FELIPE, 2010). Cabe reforçar, aqui, os dizeres de Butler (2014), para quem "a norma somente persiste como norma enquanto é atualizada na prática social e reidealizada e reinstituída durante e ao longo dos rituais sociais cotidianos da vida corporal" (p. 262). Na medida em que as crianças "já vêm de casa falando o que é de menino e de menina" (fala da professora Michele), o desafio em sala de aula é questionar rituais cotidianos naturalizados na cultura e que reforçam estigmas sociais que impedem às próprias crianças explorarem outras possibilidades de se (re)inventarem. Quando as próprias crianças aprendem a colocar em funcionamento práticas sociais de imposição (hetero)normativa, que prevê a inserção de todos os sujeitos em categorias identitárias cristalizadas e, consequentemente, limitantes, elas perdem a oportunidade para participar de outras possibilidades de aprendizagens-ensinamentos.

A professora Fernanda, sobre a ideia do que é ser menino ou menina, reitera que a criança da instituição "já vem de casa [com isso] preestabelecido. Eles já chegam dentro de sala de aula com essa noção. E às vežes acontece de falar que tal coisa é só para as meninas e tal coisa só para os meninos". Até mesmo as crianças pequenas aprendem desde cedo a propagar múltiplas e variadas formas de preconceito e discriminação, corroborando para reiterar a ideia da "normalidade" a partir do que é valorizado pelos padrões sociais hegemônicos (GUIZZO; BECK, 2014). Caminhando em dissonância com esse pensamento, frisamos a necessidade de recusarmos as "formas impostas de subjetividade para meninos e meninas [...] na construção de outros modos de estar e viver as infâncias" (SILVA; PARAÍSO, 2017, p. 2) para além da perspectiva binária de compreensão dos gêneros.

Para discutirmos as marcas de gênero no espaço da Educação Infantil, buscamos compreender as relações sociais que se estabelecem entre as crianças, e entre adultos e crianças. Longe de se constituírem enquanto "tábulas rasas", as crianças vão aprendendo com os adultos e entre seus pares através da negociação de sentidos (BAKHTIN, 2011). Nesse contexto, vale considerarmos a definição de "cultura de pares" que, segundo Corsaro (2011), é "um conjunto estável de atividades ou rotinas, artefatos, valores e preocupações que as crianças produzem e compartilham em interação com as demais" (p. 128). As culturas da infância são produzidas pelas crianças em interação com os adultos, evidenciando o quanto "seus atos de linguagem são potentes e podem dar a ver as complexas relações sociais e culturais que sempre - desde o nascimento - estabeleceram com o entorno" (RICHTER; BARBOSA, 2010, p. 93); um entorno que se dá através de práticas cotidianas envolvendo pessoas de gerações e contextos socioculturais distintos. 
A professora Júlia enfatiza o aspecto da relação adulto-criança ao acreditar que "o brincar da criança é de acordo com o olhar do adulto. À medida que o adulto vai orientando 'você não pode isso on aquilo' é o que ele vai passar para a criança". Essas relações são discutidas por Bello e Felipe (2010), para quem "o modo pelo qual as crianças se comportam, o que elas fazem ou dizem são produzidos a partir do que elas pensam ser os desejos adultos para as suas construções de gênero” (p. 176). Isso não significa que as crianças meramente "copiam" aquilo que presenciam na vida cotidiana, mas aprendem a incorporar discursos e práticas de outras pessoas aos seus próprios modos de ser e estar no mundo. Isso aponta para o quão importante é o papel mediador do adulto no espaço da Educação Infantil, principalmente em função da necessidade de que mais diálogos sobre as marcas de gêneros sejam construídos para o questionamento da produção das masculinidades e feminilidades hegemônicas.

\section{"Um pai [...] veio reclamar [com a escola] que o filho levou a boneca da Chapeuzinho Vermelho para casa"}

Algumas das professoras, ao serem questionadas sobre as possibilidades de se trabalhar gênero na escola e se as crianças têm liberdade para fabricar suas formas de ser e estar no mundo, argumentaram:

Fernanda: Sim, tenho liberdade para trabalhar. Uns seis, sete anos atrás a escola não tinha essa preocupação. Era o mesmo nivel para os dois (meninos e meninas). Essa preocupação vem de agora. Os pais não tinham essa preocupação. Está diferente. Não sei explicar o que é. É muito mais intenso que antes. Não chegava nenhum pai para mim reclamando que tem um menino rebolando igual menina. Isso vem de agora. Essa exigência dos pais de separar o que é de menino e de menina.

2

Michele: Eu ainda não cheguei a perceber isso. Pois sou nova na escola aqui. Mas teve um fato interessante. A escola estava trabalhando com literatura infantil no $1^{\circ}$ Bimestre e minha turma ficon responsável pela história da Chapeuzinho Vermelho. Na hora da confecção das lembranças para as crianças, a direção pediu para que en fizesse dois modelos: A Chapenzinho e o Lobo. Acho que teve essa intervenção da escola para que meninos não levassem para casa uma boneca. Mas na hora da distribuição, en não dei de acordo com gênero e um pai de menino veio reclamar que o filho levou a boneca da Chapeuzinho Vermelho para casa. Eu tive que trocar a lembrancinha daquela crianca, pois o pai não aceitou de jeito nenhum. Mesmo comigo conversando com ele e explicando sobre o projeto. Então acredito que a direção pediu para que eu firesse esses dois modelos para impedir que acontecesse algo parecido. Foi mais uma precaucão com relação a esses pais que não entendem que isso não tem nada a ver, pois a escola é sócio interacionista e tem muita participação dos pais e da comunidade. Então a direção tem essa preocupação.

As crianças estão inseridas num cenário em que as regras e as condutas já estão previamente determinadas. Diante disso, cabe questionarmos como as práticas sociais naturalizam-se na cultura, buscando "garantir às crianças o direito de expressar seus conhecimentos sobre os corpos e sobre as sexualidades" (PEIXOTO, 2013, p. 217), de forma que elas sejam mais livres para construir suas expressões de gênero. Ainda que o cotidiano da Educação Infantil seja um espaço interessante para se discutir as relações de gênero, muitas vezes é a família que detém o poder na reprodução da "dominação masculina”, pois é em casa que a criança, desde muito nova, vai aprendendo a reproduzir os estereótipos (GOMES, 2006). 
No que tange o compromisso social da instituição escolar, consideramos importante o planejamento de estratégias pedagógicas que coloquem em xeque normas regulatórias de gênero responsáveis pela reiteração de discursos preconceituosos e discriminatórios (SEFFNER, 2011). Ainda que a professora Fernanda não tenha fornecido mais elementos na conversa para que pudéssemos pensar sobre a relação entre a prática pedagógica atual dela e os acontecimentos passados, vale destacar o quanto vivemos hoje, na concepção dela, uma nítida preocupação por parte das famílias sobre as discussões de gênero no âmbito da Educação Infantil: “Os pais [até pouco tempo atrás]não tinham essa preocupação.[...] Não chegava nenbum pai para mim reclamando que tem um menino rebolando igual menina. Isso vem de agora. Essa exigência dos pais de separar o que é de menino e de menina". Não seria demais supor a complexidade de se discutir questões relacionadas ao tema gênero e sexualidade na escola ocorre porque cada estudante pertence a um contexto sociocultural distinto, vivenciando experiências familiares imbuídas de seus próprios valores morais (SEFFNER, 2011). Isso significa que nem todas as famílias brasileiras estão abertas ao diálogo para se discutir um tema que coloca em questão a supremacia da matriz heterossexual - a mesma supremacia que regula/conduz as práticas sociais no âmbito de inúmeras dessas famílias.

A escola, não raramente, reproduz os estigmas criados pela cultura do que é "de menino" e "de menina”. A professora Michele ressaltou que, ao trabalhar a história da Chapeuzinho Vermelho na Educação Infantil, foram confeccionadas lembranças às crianças. Entretanto, de acordo com ela, "a direção pediu para que en fizesse dois modelos: A Chapeuzinho e o Lobo. Acho que teve essa intervenção da escola para que meninos não levassem para casa uma boneca". Essa dificuldade de a escola questionar as normas regulatórias de gênero acaba naturalizando comportamentos fixos atribuídos para cada um dos gêneros (FREITAS; BRÊTAS, 2016). Cenários como esses reforçam as marcas de gênero na Educação Infantil, contribuindo para que as professoras participantes do estudo se questionassem constantemente sobre o quanto ainda precisamos desnaturalizar práticas. Caminhando com esse pensamento, Guizzo e Beck (2014) apontam que "não se pode simplesmente afirmar que 'as coisas são o que são e pronto' ou que 'essa é a realidade”' (p. 307).

Enquanto professores, temos a oportunidade na sala de aula de investir esforços que apontem para o quanto a ideia de normalidade é socialmente construída (WARNER, 1999), e o quanto a produção da normatização dos corpos, gêneros e sexualidades produz sujeitos que, ao desviarem dos padrões esperados, são colocados na condição de "diferentes", de desqualificados (SOARES, 2013). Conforme argumenta Miskolci (2010), "o silêncio de educadores diante do incômodo causado por um estudante que age de forma distinta da maioria não é uma atitude neutra. É uma tentativa de eliminá-lo” (p. 18). Consideramos ser importante ressignificar o espaço da escola, com o objetivo de constituir-se enquanto uma instituição acolhedora. Caminhando nessa direção, Silva e Silva (2016) mostram ainda que:

Assim como a família, a escola é primordial na construção do ser humano, pois o meio em que convivemos reflete de várias maneiras no caráter e nas atitudes de cada individuo. É uma instituição que interfere diretamente na situação social, isso significa que, uma sociedade desregulada pela aglomeração de conflitos e desastres, quase sempre é consequência da falta de investimentos na educação (p.9). 
A escola tem como uma de suas finalidades estimular o desenvolvimento infantil através da curiosidade e do questionamento constante. Dessa forma, reconhecendo que tanto a família quanto a escola participam de forma significativa na formação da criança, temos a oportunidade singular de planejar estratégias pedagógicas para que os próprios filhos promovam reflexões em casa em torno da naturalização da ludicidade nas diferentes brincadeiras de infância, o que significa dissociar a ideia de que o brinquedo estaria associado ao gênero do sujeito. Ao questionarmos as normas regulatórias de gênero, encorajando as crianças a participar de práticas de ensinar-aprender mais livres das garras (hetero)normativas, certamente estaremos mais próximos de construir um "um espaço livre de coerção, um cotidiano em cuja dinâmica as crianças possam se manifestar em toda sua inteireza: sentimentos, pensamento, intuição, múltiplos sentidos” (OSTETTO, 2017, p. 56).

\section{"A criança tem que ser livre. Nosso papel é fazer com que ela vivencie"}

Diante da tutela que os pais exercem sobre os filhos, Preciado (2013) nos convida a refletir a partir das seguintes perguntas: “quem defende os direitos das crianças tidas como diferentes? Quem defende os direitos da criança a crescer num mundo sem violência sexual ou de gênero?” (p. 97). A partir das perguntas formuladas por Preciado, as professoras foram instigadas a relatar as diferentes possibilidades de (re)pensarem suas próprias experiências pedagógicas no cotidiano da Educação Infantil:

1

Fernanda: Acredito que tem que ser de forma conjunta, com os pais e a escola. Tem que haver essa parceria para assegurar o direito das crianças,em todos os sentidos. Não adianta somente a escola intervir nesse assunto se em casa a criança sofre esse tipo de violência. E vice-versa.

2

Andréia: Acho que se tem um menino ou uma menina que está sofrendo com isso, o professor tem que intervir. Agora, é uma coisa muito difícil. Porque ele vem assim de casa e o pai e a mãe não aceitam. E eles vão sofrer isso até crescerem. Até chegarem a uma idade em que poderão escolher o que querem. Mas enquanto eles forem pequenos e comandados pelos pais, eles vão sofrer isso. Não por parte dos professores pois a gente tenta ajudar. Igual quando um menino pega num lápis rosa e alguém comenta algo sobre isso. Na minha sala nem tem muito isso. Falo com eles que podem colorir com qualquer cor. Podem desenhar, brincar do jeito que quiser. "Ah, mas meu pai não deixa usar lápis rosa." "Mas a tia deixa. Pode usar. Não tem problema." Tenho que mediar.

3

Michele: Na Educação Infantil, nosso papel é mostrar para ela todas as possibilidades e dar para ela o direito de escolher o que quer. A criança tem que ser livre. Nosso papel é fazer com que ela vivencie. A Educação Infantil é o primeiro passo. A gente precisa já ir trabalhando essa identidade de gênero, mostrar que não tem problema o menino usar rosa e a menina jogar bola.

Um dos atributos fundamentais da instituição escolar é o de reconhecer que determinadas práticas sociais invisibilizam grupos de sujeitos, sendo responsáveis por relegar à condição de ser abjeto ${ }^{8}$ todas aquelas pessoas que fogem aos padrões sociais colocados em funcionamento pelas (hetero)normas (MISKOLCI, 2013). Propor estratégias de enfrentamento ao regime heterocentrado (PRECIADO, 2014)

\footnotetext{
${ }^{8}$ O abjeto desestabiliza as identidades, não respeito as regras, os lugares e os limites (KRISTEVA, 2006).
} 
é um dos compromissos sociais da escola pública, ainda mais numa época em que grupos conservadores agem para manter intacta a supremacia da matriz heterossexual. Para isso, acreditamos na importância de se promover esforços e empreendimentos que desconstruam normas regulatórias de gênero; esforços e empreendimentos que sejam realizados "de forma conjunta, com os pais e a escola. Tem que haver essa parceria para assegurar o direito das crianças, em todos os sentidos" (fala da professora Fernanda). Dessa forma, ressaltamos o quanto

A escola tem a força para reproduzir sistemas de pensamento já existentes, produzir outros e também para resistir a determinados sistemas, propondo mudanças nas relações e na estrutura da sociedade. Como qualquer instituição social, ela estabelece permanente diálogo com o contexto social em que está inserida, sofrendo pressões por parte deste, mas também sinalizando para ele as demandas sociais (RIZZATO, 2013, p.42).

Diante do fato de a instituição escolar estar inserida na estrutura social, nem sempre é tarefa fácil envolver toda comunidade escolar na luta contra as ideologias que alimentam a imposição das normas regulatórias de gênero. Defendemos que as professorasda Educação Infantil focalizem seus esforços pedagógicos no questionamento das normas que regulam corpos, gêneros e sexualidades (BELLO; FELIPE, 2010); normas responsáveis pela produção de estigmas sociais que desqualificam todos os alunos que são colocados na posição de "desviantes" dessas mesmas normas. Consideramos que um dos aspectos mais cruéis para reiterar/reatualizar as normas regulatórias de gênero na escola ocorre quando "educadores adotam o silêncio diante da emergência de uma sexualidade [ou comportamento tido como] diferente e, assim, tornam-se cúmplices da ridicularização e do insulto público de alguns estudantes" (MISKOLCI, 2010, p. 18).

Louro (2010) salienta que "precisamos, enfim, nos voltar para práticas que desestabilizem e desconstruam a naturalidade" (p. 51), ou seja, práticas que possam questionar a força discursiva dos pilares que sustentam a normalização da vida. Essas práticas podem incluir atitudes aparentemente simples, mas que desencadeiam contribuições significativas para o cotidiano da Educação Infantil, conforme explicita a professora Andréia: "Falo com eles que podem colorir com qualquer cor. Podem desenhar, brincar do jeito que quiser. 'Ah, mas meu pai não deixa usar lápis rosa.' 'Mas a tia deixa. Pode usar. Não tem problema.' Tenho que mediar'. Ao evidenciar para as crianças a ideia de que todas as vidas merecem ser vividas, essas mediações-conversas promovem a defesa de uma democracia aberta, "o que significa o direito de sair à rua sem medo, o direito [...] de se associar livremente com aqueles com quem se escolhe, sem intervenção e sem patologização" (BUTLER, 2017, p. 40).

Conforme a professora Michele relatou, "nosso papel [na Educação Infantil] é mostrar para ela [criança] todas as possibilidades e dar para ela o direito de escolher o que quer. A criança tem que ser livre. Nosso papel é fazer com que ela vivencie". Butler (2017) caminha nessa direção e diz que "quando exercemos o direito de ser o gênero que somos ou quando exercemos o direito à sexualidade que não causa prejuízo a ninguém, então estamos exercendo uma certa liberdade (p. 36). E essa liberdade, conclui a autora, "deve ser 
protegida" (p. 36). Para isso, almejamos que as crianças da Educação Infantil façam parte de um ambiente acolhedor que potencialize suas múltiplas e variadas formas de ver-sentir o mundo.

\section{Considerações Finais}

Toda vez que criamos expectativas sociais para cada gênero, reforçamos a supremacia de um regime patriarcal vigente (PRECIADO, 2014). Enquanto profissionais do campo da educação, defendemos a necessidade de se abordar, em parceria com a equipe pedagógica e com as famílias das crianças, questões relacionadas às marcas de gênero. Nem sempre essa prática vem sendo exercitada, o que acarreta num trabalho que, feito de forma fragmentada e isolada, promove certa aflição em algumas professoras, que ainda consideram o tema como um tabu.

Cabe salientar que a influência da família na construção das masculinidades e das feminilidades está presente nas relações do brincar das crianças no dia a dia da Educação Infantil. Diante disso, consideramos importante buscar estratégias/brechas capazes de promover diálogos mais abertos entre a escola, as crianças e as famílias, com o objetivo de negociar sentidos que possam ser potentes para diminuir a incidência de preconceitos e discriminações em torno das questões de gênero, que estremecem o cotidiano da Educação Infantil. Não somos ingênuos ao acreditar que o trabalho não envolva desafios e tensões, principalmente com a tutela exercida pelos pais sobre os filhos e o cuidado excessivo da escola em não discutir gênero, por ainda considerá-lo tabu ou um tema que deve ser abordado exclusivamente no âmbito familiar das crianças.

Somando-se a isso, a chamada "ideologia de gênero" também não vem facilitar o trabalho pedagógico das professoras da Educação Infantil, que se sentem pouco confortáveis na formulação de atividades pedagógicas que possam caminhar na contramão de propostas construídas por grupos religiosos ultraconservadores. Enquanto essas propostas de cunho homofóbico continuarem defendendo a supremacia das normas regulatórias de gênero, é imprescindível continuarmos lutando por uma educação pública de qualidade que assegure o direito das crianças de se (re)afirmarem para além da simplória categoria social menino/menina, que busca limitar a potência dos corpos. Conforme nos lembra Guizzo e Beck (2014), “as coisas não seguem sendo sempre o que são, seguindo um 'padrão' previamente estabelecido. Nelas podemos intervir para que saiamos de essencialismos até hoje tão arraigados" (p. 307).

Reconhecer a brincadeira e o lúdico como aspectos constituintes do ser criança e do viver a infância nos permite assegurar às crianças o direito de se expressarem livremente nas escolas ao experimentarem novas formas de (re)imaginar o mundo (BROUGÈRE, 1998). Não há como negar que os jogos e as brincadeiras proporcionam a colaboração entre as crianças, que vivenciam situações imaginárias no desenvolvimento, permitindo que o potencial criativo delas seja atingido (KISHIMOTO, 2002). Colocar em prática uma educação atenta à importância do lúdico nas dinâmicas do ensinar-aprender das crianças significa questionar práticas educativas "engessadas" que buscam separar, de um lado, os corpos que teriam permissão para jogar bola e, de outro lado, os corpos que poderiam usar rosa. 
Adichie (2017) evidencia a importância de educar crianças a partir da premissa da igualdade de gênero ao destacar que os processos educativos são importantes no questionamento das normas regulatórias de gênero. A autora concorda que "se não empregarmos a camisa de força do gênero nas crianças pequenas, daremos a elas espaço para alcançar todo seu potencial” (p. 26). Acreditamos o quanto ainda precisamos "torcer", enfraquecer essas normas regulatórias de gênero ao aprendermos com as crianças que o ato de brincar não deveria ser excludente, pois favorece a (re)criação de outros mundos (im)possíveis. Nos amparamos em Seffner (2013) e caminhamos numa direção oposta àquela que defende que "é de pequenino que se torce o pepino" (p. 149). Acreditamos no papel transformador das práticas pedagógicas na promoção de amplas possibilidades de viver-experimentar das crianças através da partilha de sentidos produzidos nos cotidianos da Educação Infantil.

\section{Referências}

ADICHIE, Chimamanda Ngozi. Para educar crianças feministas: um manifesto. Tradução de Denise Bottmann. São Paulo: Companhia das Letras, 2017.

ALVES, Nilda. Políticas e cotidianos em redes educativas e em escolas. XVI ENDIPE - Encontro Nacional de Didática e Práticas de Ensino - UNICAMP - Campinas - 2012.

AMARO, Ivan. A docência no armário: o silenciamento das relações de gênero nos planos de educação. Espaço Pedagógico, Passo Fundo, v. 24, n. 1, p. 139-159, jan./abr. 2017.

AMORIM, Marilia. Cronotopo e exotopia. In: BRAIT, Beth (Org.). Bakhtin: outros conceitos-chave. São Paulo: Contexto, 2008, p. 95-114.

BAKHTIN, Mikhail. Estética da criação verbal. Tradução de Paulo Bezerra. 6. Ed. São Paulo: Martins Fontes, 2011.

BELLO, Alexandre Toaldo; FELIPE, Jane. Delineando masculinidades desde a infância. Revista Instrumento, Juiz de Fora, v. 12, n. 2, jul/dez. 2010.

BENTO, Berenice. Na escola se aprende que a diferença faz a diferença. Revista Estudos Feministas, Florianópolis, v. 19, n. 2, p. 549-559, maio/ago. 2011.

BROUGÈRE, Gilles. A criança e a cultura lúdica. Revista da Faculdade de Educação, São Paulo, v. 24, n. 2, p. 103-116, jul./dez. 1998.

BUTLER, Judith. Alianças queer e política anti-guerra. Bagoas - Estudos Gays: gênero e sexualidades, v. 11, n. 16, p. 29-49, 2017.

BUTLER, Judith. Regulações de gênero. Cadernos Pagu, Campinas, n. 42, p. 249-274, jan./jun. 2014. 
BUTLER, Judith. Quadros de guerra: quando a vida é passível de luto. Rio de Janeiro: Civilização Brasileira, 2015.

BORRILLO, Daniel. Homofobia: história e crítica de um preconceito. Tradução de Guilherme João de Freitas Teixeira. Belo Horizonte: Autêntica Editora, 2010.

CARVALHO, Maria Cristina. Infância, leitura e escrita - entrando numa escola de formação de professores. In: FAZOLO, Eliane; CARVALHO, Maria Cristina; LEITE, Maria Isabel; KRAMER, Sonia. (Orgs.). Educação infantil em curso. Rio de Janeiro: Ravil, 1997, p. 96-124.

CORNEJO-VALLE, Mónica; PICHARDO, J. Ignacio. La “ideología de género" frente a losderechossexuales y reproductivos. El escenarioespañol. Cadernos Pagu, Campinas, n. 50, 2017.

CORSARO, William. Sociologia da infância. Tradução de Lia Gabriele Regius Reis. 2. Ed. Porto Alegre: Artmed, 2011.

COUTO JUNIOR, Dilton Ribeiro. Marcas da abjeção expressas em conversas sobre heteronormatividade com jovens no Facebook: em defesa de uma pedagogia queer. 2017. 290f. Tese (Doutorado em Educação) - Faculdade de Educação, Universidade do Estado do Rio de Janeiro, Rio de Janeiro, 2017.

COUTO JUNIOR, Dilton Ribeiro; FERREIRA, Helenice Mirabelli Cassino; OSWALD, Maria Luiza Magalhães Bastos. Compartilhando experiências sobre o "armário": as conversas online como procedimento metodológico da pesquisa histórico-cultural na cibercultura. Interfaces Científicas Educação, Aracaju, v. 6, n. 1, p. 23-34, out. 2017.

COUTO JUNIOR, Dilton Ribeiro; OSWALD, Maria Luiza Magalhães Bastos. "Tudo o que você disser vira pesquisa": trilhando caminhos teórico-metodológicos na pesquisa com internautas. Revista Teias, Rio de Janeiro, v. 17, p. 179-193, 2016.

FREITAS, Maria José Dias de; BRÊTAS, José Roberto da Silva. Estigma e preconceito na Educação Infantil e anos iniciais do Ensino Fundamental. Gênero, Niterói, v. 17, n. 1, p. 105-122, dez. 2016.

FREITAS, Maria Teresa de Assunção. A abordagem sócio-histórica como orientadora da pesquisa qualitativa. Cadernos de Pesquisa, n. 116, p. 21-39, jul. 2002.

FREITAS, Maria Teresa de Assunção. A pesquisa de abordagem histórico-cultural: um espaço educativo de constituição de sujeitos. Revista Teias, Rio de Janeiro, v. 10, n. 19, p. 1-12, 2009.

FURLANI, Jimena. Sexos, sexualidades e gêneros: monstruosidades no currículo da educação sexual. Educação em Revista, Belo Horizonte, n. 46. p. 269-285, dez. 2007.

GOMES, Vera Lúcia de Oliveira. A construção do feminino e do masculino no processo de cuidar de crianças em pré-escolas.Texto Contexto - Enfermagem, Florianópolis, v. 15, n. 1, p. 35-42, fev. 2006. 
GUIZZO, Bianca Salazar; BECK, Dinah Quesada. Corpos depreciados: representações de gênero e geração na infância. Quaestio, Sorocaba, v. 16, n. 2, p. 297-313, nov. 2014.

JOBIM E SOUZA, Solange; ALBUQUERQUE, Elaine Deccache Porto. A pesquisa em ciências humanas: uma leitura bakhtiniana. Bakhtiniana, São Paulo, v. 7, n. 2, p. 109-122, jul./dez. 2012.

JOBIM E SOUZA, Solange; SALGADO, Raquel Gonçalves. Mikhail Bakhtin e a ética das imagens nos estudos da infância: uma proposta de pesquisa-intervenção. In: CASTRO, Lucia Rabello; BESSET, Vera Lopes (Orgs.). Pesquisa-intervenção na infância e juventude. Rio de Janeiro: Trarepa/FAPERJ, 2008, p. $490-513$.

JUNQUEIRA, Rogério Diniz. "Ideologia de gênero": a gênese de uma categoria política reacionária - ou: a promoção dos direitos humanos se tornou uma "ameaça à família natural”? In: RIBEIRO, Paula Regina Costa; MAGALHÃES, Joanalira Corpes (Orgs.). Debates contemporâneos sobre educação para a sexualidade. Rio Grande: Ed. da FURG, 2017, p. 25-52.

KISHIMOTO, Tizuko. O jogo, a criança e a educação. São Paulo: Vozes, 2002.

KRAMER, Sonia. Por entre as pedras: arma e sonho na escola. 3. Ed. São Paulo: Ática, 2007.

KRAMER, Sonia. Professoras de educação infantil e mudança: reflexões a partir de Bakhtin. Cadernos de Pesquisa, v. 34, n. 122, p. 497-515, maio/ago. 2004.

KRISTEVA, Julia. Poderes de la perversión: ensayo sobre Louis-Ferdinand Céline. 6 Ed. Madrid: Siglo XXI editores, 2006.

LOURO, Guacira Lopes. Um corpo estranho: ensaios sobre sexualidade e teoria queer. 2 Ed. Belo Horizonte: Autêntica, 2013.

LOURO, Guacira Lopes. O corpo educado: pedagogias da sexualidade. 2 Ed. Belo Horizonte: Autêntica, 2000

LOURO, Guacira Lopes. Currículo, gênero e sexualidade - O "normal", o "diferente" e o "excêntrico". In: LOURO, Guacira Lopes; FELIPE, Jane; GOELLNER, Silvana Vilore (Orgs.). Corpo, gênero e sexualidade: um debate contemporâneo na educação. 6 Ed. Petrópolis, RJ: Vozes, 2010, p. 41-52.

MEYER, Dagmar Estermann. Gênero e educação: teoria e política. In: LOURO, Guacira Lopes; FELIPE, Jane; GOELLNER, Silvana Vilore (Orgs.). Corpo, gênero e sexualidade: um debate contemporâneo na educação. 6 Ed. Petrópolis, RJ: Vozes, 2010, p. 9-27.

MISKOLCI, Richard. Um corpo estranho na sala de aula. In: ABRAMOWICZ, Anete; SILVERIO, Valter Roberto (Orgs.). Afirmando diferenças: montando o quebra-cabeça da diversidade na escola. 2 Ed. Campinas: Papirus, 2010, p. 13-26. 
MISCKOLCI, Richard. Teoria queer: um aprendizado pelas diferenças. 2 Ed. Belo Horizonte: Autêntica, 2013.

OSTETTO, Luciana Esmeralda. Sobre a organização curricular da Educação Infantil: conversas com professoras a partir das Diretrizes Curriculares Nacionais. Revista Zero-a-seis, Florianópolis, v. 19, n. 35, p. 46-68, jan./jun 2017.

PARAÍSO, Marlucy Alves. A ciranda do currículo com gênero, poder e resistência. Currículo Sem Fronteiras, v. 16, n. 3, p. 388-415, set./dez. 2016.

PEIXOTO, Leonardo Ferreira. Crianças e discursos sobre os corpos nos cotidianos escolares.Revista Instrumento, Juiz de Fora, v. 15, n. 2, p. 211-218, jul./dez. 2013.

PRECIADO, Paul Beatriz. Manifesto contrassexual: Práticas subversivas de identidade sexual. Tradução de Maria Paula Gurgel Ribeiro. São Paulo: n-1 Edições, 2014.

PRECIADO, Paul Beatriz. Quem defende a criança queer? Jangada, Viçosa, n. 1, p. 96-99, jan./jun. 2013.

PEREIRA, Rita Marisa Ribes. Pesquisa com crianças. In: PEREIRA, Rita Marisa Ribes; MACEDO, Nélia Mara Rezende (Orgs.). Infância em pesquisa.Rio de Janeiro: Nau, 2012, p. 59-86.

PEREIRA, Rita Marisa Ribes. Por uma ética da responsividade: exposição de princípios para a pesquisa com crianças. Currículo Sem Fronteiras, v. 15, n. 1, p. 50-64, jan./abr. 2015.

PEREIRA, Rita Marisa Ribes; SALGADO, Raquel Gonçalves; JOBIM E SOUZA, Solange. Pesquisador e criança: dialogismo e alteridade na produção da infância contemporânea. Cadernos de Pesquisa, v. 39, n. 138, p. 1019-1035, set./dez. 2009.

RIBEIRO, Paula Regina Costa; SOUZA, Nádia Geisa Silveira de; SOUZA, Diogo Onofre. Sexualidade na sala de aula: pedagogias escolares de professoras das séries iniciais do Ensino Fundamental. Revista Estudos Feministas, Florianópolis, v. 12, n. 1, p. 109-129, jan./abril 2004.

RICHTER, Sandra Regina Simonis; BARBOSA, Maria Carmem Silveira. Os bebês interrogam o currículo: as múltiplas linguagens na creche. Educação, Santa Maria, v. 35, n. 1, p. 85-96, jan./abr. 2010.

RIZZATO, Liane Kelen. Percepções de professores/as sobre gênero, sexualidade e homofobia: pensando a formação continuada a partir de relatos da prática docente. 2013. 278f. Dissertação (Mestrado em Sociologia da Educação). Faculdade de Educação da Universidade de São Paulo, São Paulo, 2013.

ROSADO-NUNES, Maria José Fontelas. A “ideologia de gênero” na discussão do PNE: a intervenção da hierarquia católica. Horizonte, Belo Horizonte, v. 13, n. 39, p. 1237-1260, jul./set. 2015. 
SARMENTO, Manuel Jacinto. Gerações e alteridade: interrogações a partir da sociologia da infância.

Educação \& Sociedade, Campinas, v. 26, n. 91, p. 361-378, maio./ago. 2005.

SEFFNER, Fernando. Sigam-me os bons: apuros e aflições nos enfrentamentos ao regime da heteronormatividade no espaço escolar. Educação e Pesquisa, São Paulo, v. 39, n. 1, p. 145- 159, jan./mar. 2013.

SEFFNER, Fernando. Um bocado de sexo, pouco giz, quase nada de apagador e muitas provas: cenas escolares envolvendo questões de gênero e sexualidade. Revista Estudos Feministas, Florianópolis, v. 19, n. 2, p. 561-572, maio/ago. 2011.

SIERRA, Jamil Cabral; CÉSAR, Maria Rita de Assis. A criança queer no cinema e as subversões das normas de gênero e sexualidade na escola. Revista Reflexão e Ação, Santa Cruz do Sul, v. 24, n. 1, p. 4760, jan./abr. 2016.

SILVA, João Paulo de Lorena; PARAÍSO, Marlucy Alves. Bagunçando as normas de gênero: crianças transviadas e a invenção de outros possíveis no currículo escolar. In: SEMINÁRIO INTERNACIONAL DE ESTUdOS CULTURAIS E EDUCAÇÃO, 4., 2017, Canoas. Anais... Canoas: ULBRA, 2017, 13p.

SILVA, Romyson dos Santos da; SILVA, Quilza da Silva e.Sexo, gênero e poder: um olhar sobre o processo de construção das identidades no cotidiano escolar. In: SEMINÁRIO NACIONAL DEMANDAS SOCIAIS E POLÍTICAS PÚBLICAS NA SOCIEDADE CONTEMPORÂNEA. 12., 2016, Santa Cruz do Sul. Anais... Santa Cruz do Sul: Universidade de Santa Cruz do Sul, 2016.

SOARES, Maria da Conceição Silva. A produção da diferença no cotidiano das escolas: currículo, representação, significação e devir. In: RODRIGUES, Alexsandro; BARRETO, Maria Aparecida (Orgs.). Currículos, gêneros e sexualidades: experiências misturadas e compartilhadas. Vitória: Edufes, 2013, p. 83-102.

WARNER, Michael. Introduction. In: WARNER, Michael (Org.). Fear of a queer planet: queer politics and social theory. 6 Ed. London: Universityof Minnesota Press, 2004, p. vii-xxxi.

WARNER, Michael. The trouble with normal: sex, politics, and the ethics of queer life. Massachusetts: Harvard University Press, 1999 